\title{
EFFECTS OF PELVIC FLOOR MUSCLE TRAINING DURING PREGNANCY
}

\author{
Claudia de Oliveira, Marco Antonio Borges Lopes, Luciana Carla Longo e \\ Pereira, Marcelo Zugaib
}

\begin{abstract}
Oliveira C de, Lopes MAB, Longo e Pereira LC, Zugaib M. Effects of pelvic floor muscle training during pregnancy. Clinics. 2007;62(4):439-46.
\end{abstract}

OJETIVE: The objective of the present study was to evaluate the effect of pelvic floor muscle training in 46 nulliparous pregnant women.

METHODS: The women were divided into 2 groups: an exercise group and a control group. Functional evaluation of the pelvic floor muscle was performed by digital vaginal palpation using the strength scale described by Ortiz and by a perineometer (with and without biofeedback).

RESULTS: The functional evaluation of the pelvic floor muscles showed a significant increase in pelvic floor muscle strength during pregnancy in both groups $(P<.001)$. However, the magnitude of the change was greater in the exercise group than in the control group $(47.4 \%$ vs. $17.3 \%, P<.001)$. The study also showed a significant positive correlation (Spearman's test, $r=0.643 ; P$ $<.001$ ) between perineometry and digital assessment in the strength of pelvic floor muscles.

CONCLUSIONS: Pelvic floor muscle training resulted in a significant increase in pelvic floor muscle pressure and strength during pregnancy. A significant positive correlation between functional evaluation of the pelvic floor muscle and perineometry was observed during pregnancy.

KEYWORDS: Exercise and movement techniques. Pelvic floor. Musculoskeletal diseases. Perineum. Pregnancy.

Brief summary: To evaluate the effects of pelvic floor muscle training during pregnancy by evaluation of pelvic floor muscle function of the pelvic floor and by perineometry. The analysis of the effects of functional evaluation of the pelvic floor revealed a significant increase in pelvic floor muscle strength during pregnancy.

\section{INTRODUCTION}

Vaginal delivery has been recognized as an important factor in the genesis of urinary incontinence due to the fact that it can damage the pelvic floor and consequently weaken or alter the supporting structures in the pelvis. ${ }^{1,2}$ Within this context, pelvic floor muscle training (PFMT) may be an

Department of Obstetrics, São Paulo University Medical School, Brazil Email: marcoabl@terra.com.br or claufisio2005@yahoo.com.br

Received for publication on April 04, 2007

Accepted for publication on May 8, 2007. auxiliary tool for relieving the musculoskeletal alterations observed during pregnancy and the puerperal period, which is also associated with urinary incontinence. Pelvic floor muscle training is aimed at strengthening the striated musculature that is part of the striated urogenital sphincter muscle responsible for the occlusion of the urethral lumen after correct contraction of the pelvic floor. ${ }^{3,4}$

Various PFMT protocols in nonpregnant women have been reported in literature; however, the number of repetitions as well as the duration of contraction and rest between series have not been totally defined in any single protocol. ${ }^{4-}$ 9 The recommended frequency of PFMT ranges from 2 to 3 times a week for up to a 3-month period, an amount of time necessary to obtain minimum hypertrophy and, consequently, muscle strength. ${ }^{10}$

Although various studies have confirmed the efficiency of PFMT in the treatment of urinary incontinence, reports regarding PFMT for the pelvic floor muscles during preg- 
nancy and the puerperal periods are scarce. ${ }^{6,7,9,11}$ Several methods have been used to analyze pelvic floor function and dysfunction in women, including digital palpation and intravaginal devices, such as a perineometer, to assess muscular function and ability to generate pressure. ${ }^{12-17}$ But few studies refer to such methods in the evaluation of the PFM during pregnancy and puerperium. ${ }^{4,6,7,18}$ Therefore, the aim of the present study was to evaluate the effects of the PFMT during pregnancy in a population of nulliparous pregnant women, using a perineometer and digital examination.

\section{MATERIALS AND METHODS}

\section{Study Population}

A comparative, prospective, nonrandomized, longitudinal, controlled study was conducted on nulliparous pregnant women receiving prenatal care at the Low-Risk Sector of the Department of Obstetrics, University Hospital, University of São Paulo, between November 2003 and December 2004. The research protocol was approved by the Ethics Committees of the Discipline of Obstetrics, Department of Obstetrics and Gynecology, University of São Paulo Medical School, and of the University Hospital. All patients invited to participate in the study received detailed information about the research proposal and signed a consent form.

Patients with a gestational age of up to 20 weeks were selected. The patients receiving prenatal care at the Low-Risk Sector were referred to the physiotherapist in charge of the study for an interview. On the day of their routine visit, each patient was assigned to one of the two study groups described below according to her availability to access the hospital facilities for the PFMT. Patients with medical conditions that required follow-up at the Intermediate or High-Risk Pregnancy Sectors were excluded from the study, as were patients with paradoxical contraction of the pelvic floor muscles (defined as pelvic floor muscle descent, in which instead of actively squeezing and lifting the pelvic floor muscles upward, the pelvic floor is pushed downward). ${ }^{3,5,16}$ Women with preterm delivery as well as patients who missed a specified number of the evaluations were also excluded.

The sample size was calculated using preconstructed tables. ${ }^{19}$ To obtain a power of test of $80 \%$ and a level of significance of $5 \%$, the minimum number per group was calculated to be 23 patients.

Forty-six patients were included in the study and divided into the following two groups: an exercise group $(n=23)$, consisting of patients who practiced PFMT, and a control group $(n=23)$, consisting of patients who did not practice PFMT. All patients were evaluated at 2 distinct points in time (up to 20 weeks of gestation, and at 36 weeks of ges- tation). Repeated measure analysis of variance (ANOVA) was used for this analysis. Patients in the control group only returned for physiotherapeutic assessment that followed a standard protocol. General data collected included patient name, address, age, weight, height, and gestational time as well as the patient's musculoskeletal symptoms.

\section{Evaluation of the pelvic floor muscles}

First, the patient was questioned regarding her knowledge of the pelvic floor muscles. She then received information about the location and function, and on how to correctly contract this musculature. The patient was then instructed to "squeeze and lift" the pelvic floor muscles.

Next, inspection, palpation, functional evaluation of the pelvic floor (FEPF), and perineometry were consecutively performed with the patient in the gynecological position.

\section{Functional evaluation of the pelvic floor (FEPF)}

While in position, the patient was asked to perform a selective contraction of the pelvic floor muscles. Simultaneous contractions of other muscles were visually identified by the physiotherapist allowing him to better guide and correct the patient.

Functional evaluation of the pelvic floor was performed by introducing the index and middle fingers 2 to 3 centimeters into the vaginal introitus performing an abduction movement while the patient was asked to perform a maximum contraction of the muscles. The previously validated Ortiz Scale ${ }^{14,18}$, which allows the analysis of pelvic floor muscle function, was used for this evaluation. The pelvic floor muscle function was classified as follows: grade 1 = weak contraction recognized upon palpation; grade 2 = contraction present and recognized upon palpation; grade $3=$ contraction present with opposing resistance shorter than 5 seconds; grade $4=$ contraction present with opposing resistance longer than 5 seconds.

\section{Perineometry}

For the perineometry, the patient was kept in the gynecological position while a rubber-coated, uninflated transducer covered with a condom was introduced 2 to 3 $\mathrm{cm}$ into the vaginal introitus. Next, the transducer was inflated, and the apparatus was set to zero. The patient was then asked to inhale and perform maximum contraction of the pelvic floor muscles while exhaling, corresponding to perineometry without biofeedback (PNB). This procedure was repeated 3 times at intervals of 1 minute to avoid fatigue of the pelvic floor muscles. After this phase, the apparatus was positioned in such a way as to permit the patient to follow her contraction on the monitor. The patient 
then underwent perineometry with biofeedback (PWB), performing 3 new maximum contractions.

In the present study, the last of the PNB and PWB measurements was considered to be valid, because at the time of the third measurement the patient had reduced the use of accessory musculature as much as possible and had learned how to perform a correct maximum contraction of the pelvic floor muscles. Observation of a correct pelvic floor muscle contraction can be made clinically. ${ }^{16}$ All patients had obtained appropriate contraction of the pelvic floor muscles in the first session after receiving an explanation about the pelvic floor muscles with vaginal palpation.

A Perina 996-2 (Quark, São Paulo, Brazil) perineometer equipped with a vaginal transducer was used. The apparatus was calibrated 3 times during the study by the Institute for Weights and Measures and certified by the National Sanitary Surveillance Agency (ANVISA). The measurement unit was millimeters of mercury $(\mathrm{mm} \mathrm{Hg})$.

\section{Pelvic floor muscle training (PFMT)}

For the weekly sessions of PFMT, the patients came to the hospital where they remained for 1 hour and were seen in groups of 3 or 4 .

The protocol described by $\mathrm{Bo}^{5}$ was used for PFMT, and the training was divided into 2 phases: outpatient and at home. The outpatient PFMT sessions were started between 18 and 20 weeks of gestation and lasted 12 consecutive weeks. The sessions consisted of 4 series of 10 contractions each lasting 6 $\mathrm{sec}$ followed by $12 \mathrm{sec}$ of relaxation in 4 different positions (sitting, lateral decubitus, dorsal decubitus with a 45-degree elevation, and standing). The patients were instructed to exercise at home once a day. All patients in the exercise group received written instructions and started the practice concomitantly with the training received at the hospital.

\section{Statistical analysis}

All variables were submitted to descriptive analysis, with calculation of the mean, standard deviation, median, and range for quantitative variables and of absolute and relative frequencies for qualitative variables. ${ }^{19,20}$

Means were compared between the two groups using the Student $t$ test. Data not showing normal distribution were compared using the nonparametric Mann-Whitney test. The chi-square test or Fisher exact test was used to verify the homogeneity of the groups in terms of proportions. The correlation between 2 quantitative variables was determined using the Spearman correlation coefficient. Repeated measures ANOVA was used to evaluate the behavior of the groups under the conditions studied, with the hypotheses being tested by Wilks statistic with approximation for the F statistic. ${ }^{21}$ Qualitative variables were compared in the same patient before and after delivery using the nonparametric McNemar test. The level of significance was set at 5\% for all tests. Statistical analysis was performed using SPSS for Windows version 10.

\section{Characterization of the study population}

Patient ages ranged from 18 to 37 years, with a mean ( \pm standard deviation) of $25 \pm 5.4$ years. Ages ranged from 18 to 34 years in $80 \%$ of the exercise group and from 18 to 32 years in the control group, with no significant difference between groups. There was no significant difference between groups in terms of gestational age at delivery $(P=$ .480). The mean gestational age was $39.5 \pm 1.3$ weeks in the exercise group and $39.2 \pm 1.2$ weeks in the control group (Table 1).

Table 1 - Mean and standard deviation of age and gestational age of the 46 patients studied (control and exercise groups) (HCFMUSP, November 2003 to December 2004).

\begin{tabular}{lccc}
\hline & Control group & Exercise group & $P^{*}$ \\
\hline Age & $24.13 \pm 4.68$ & $25.96 \pm 6.18$ & .265 \\
Gestational age at delivery & $39.2 \mathrm{w} \pm 1.2$ & $39.5 \mathrm{w} \pm 1.3$ & .480 \\
\hline
\end{tabular}

* Student $t$ test

Using the classification of Rosso, ${ }^{22}$ no difference in weight during pregnancy was observed between the two groups, with $28.3 \%$ of the 46 pregnant women being above normal in weight. With respect to educational level, $84 \%$ (39 cases) of the patients had more than 8 years of schooling, and none of them was illiterate. No significant difference in this parameter was observed between groups. The evaluation of race (white or nonwhite) showed a predominance of whites in the exercise $(65.2 \%)$ and control (56.5\%) groups, with no significant difference between groups $(P=$ .546) (Table 2).

Table 2 - Distribution of the 46 patients studied (control and exercise groups) regarding the results of race and weight during pregnancy (HCFMUSP, November 2003 to December 2004).

\begin{tabular}{llccccc}
\hline \multirow{2}{*}{ Variable } & & \multicolumn{3}{c}{ Control group } & \multicolumn{3}{c}{ Exercise group } & \multirow{2}{*}{ ( } \\
& & $\mathrm{n}$ & $\%$ & $\mathrm{n}$ & $\%$ & $P^{*}$ \\
\hline Race & White & 13 & 56.5 & 15 & 65.2 & .546 \\
& Nonwhite & 10 & 43.5 & 8 & 34.8 & \\
& & & & & & \\
Weight & Underweight & 10 & 43.5 & 9 & 39.1 & \\
& Normal & 7 & 30.4 & 7 & 30.4 & $>.999$ \\
& Overweight & 2 & 8.7 & 3 & 13.1 & \\
& Obese & 4 & 17.4 & 4 & 13.4 & \\
Educational level & $>8$ years & 15 & 65.22 & 14 & 60.87 & .626 \\
\hline
\end{tabular}

*Fisher exact test 


\section{RESULTS}

\section{Functional evaluation of the pelvic floor (FEPF)}

No difference in FEPF was observed between groups at the 1st examination (20 weeks of gestation). However, the McNemar test revealed a significant change from the 1st (20 weeks of gestation) to the 2nd examination (36 weeks of gestation) in both the exercise and control groups, with a larger number of grade 3 or 4 cases being observed at the 2 nd examination in both groups. Proportionally, a larger number of cases increasing from grade 1 or 2 to grade 3 or 4 was observed in the exercise group, with the difference between the two groups being significant $(P=.048)$ (Table 3 ).

Table 3 - Distribution of the 46 patients studied (control and exercise groups) regarding the results of functional evaluation of the pelvic floor (FEPF) at the 1st (20 weeks of gestation) and 2nd examination (36 weeks of gestation) (HCFMUSP, November 2003 to December 2004).

\begin{tabular}{lccccccc}
\hline & \multicolumn{3}{c}{ Control $(\mathrm{n}=23)$} & \multicolumn{3}{c}{ Exercise $(\mathrm{n}=23)$} \\
& Grades & $P^{*}$ & Grades & $P^{*}$ & Grades & $P^{*}$ & Grades \\
& $1-2$ & & $3-4$ & & $1-2$ & $3-4$ \\
\hline $1^{\text {st }}$ examination & 13 & & 10 & & 14 & 9 \\
$2^{\text {nd }}$ examination & 8 & & 15 & & 4 & & 19 \\
& & .025 & & .048 & & .004 & \\
\hline
\end{tabular}

* McNemar test.

\section{Perineometry}

No difference in the PNB or PWB results was observed between groups at the 1st examination (Table 4). Comparisons of PNB and PWB at the 1st (20 gestational weeks) and 2nd examination (36 gestational weeks) by repeated ANOVA measures revealed a significant difference between the exercise and control groups $(P=.021$ for PNB and $P=$ .005 for PWB). A numerical increase in PNB and PWB from the 1 st to the 2 nd examination was observed in the two groups.

Table 4 - Perineometry results obtained for the 46 patients at the first examination (HCFMUSP, November 2003 to December 2004).

\begin{tabular}{lccc}
\hline & Control $(\mathrm{n}=23)$ & Exercise $(\mathrm{n}=23)$ & $P^{*}$ \\
\hline PNB $\left(1^{\text {st }}\right.$ examination $)$ & $9.15 \pm 5.63$ & $8.16 \pm 4.66$ & .519 \\
PWB $\left(1^{\text {st }}\right.$ examination $)$ & $9.01 \pm 4.44$ & $8.85 \pm 4.24$ & .901
\end{tabular}

Values are reported as mean \pm standard deviation.

* Student $t$ test.

$\mathrm{PNB}=$ perineometry without biofeedback;

$\mathrm{PWB}=$ perineometry with biofeedback.
Regarding PNB, the exercise group showed a significant increase at the 2nd examination $(P<.001)$, which was not observed for the control group $(P=.139)$. With respect to PWB, a significant increase was observed at the 2nd examination both in the exercise $(P<.001)$ and control $(P=$ $.017)$ groups (Table 5). However, the delta variation was higher in the exercise group $(47.37 \%)$ than in the control group (17.28\%).

Table 5 - Results of perineometry with (PWB) and without (PNB) biofeedback obtained for the 46 pregnant women (control and exercise groups) at the first and second examinations (HCFMUSP, November 2003 to December 2004).

\begin{tabular}{|c|c|c|c|c|}
\hline & Control $(n=23)$ & $P$ & Exercise $(\mathrm{n}=23)$ & $P$ \\
\hline \multicolumn{5}{|l|}{ PNB } \\
\hline 1st examination & $9.15 \pm 5.63$ & & $8.16 \pm 4.66$ & \\
\hline 2nd examination & $10.22 \pm 4.01$ & .137 & $11.63 \pm 3.80$ & $<.001$ \\
\hline \multicolumn{5}{|l|}{ PWB } \\
\hline 1st examination & $9.15 \pm 5.63$ & & $8.16 \pm 4.66$ & \\
\hline 2nd examination & $10.57 \pm 4.02$ & .017 & $13.04 \pm 4.72$ & $<.001$ \\
\hline \multicolumn{5}{|c|}{ Values are reported as mean \pm standard deviation. } \\
\hline \multicolumn{5}{|c|}{ Correlation between perineometry and FEPF } \\
\hline \multicolumn{5}{|c|}{ A significant positive correlation between FEPF and } \\
\hline \multirow{2}{*}{\multicolumn{5}{|c|}{$\begin{array}{l}\text { perineometry without biofeedback (PNB) (Table 6) as well } \\
\text { as between FEPF and perineometry with biofeedback (PWB) }\end{array}$}} \\
\hline & & & & \\
\hline \multicolumn{5}{|c|}{ (Table 7) was observed in both the control and exercise } \\
\hline
\end{tabular}

Table 6 - Spearman correlation coefficients for functional evaluation of the pelvic floor (FEPF) and perineometry without biofeedback (PWB) obtained at the first and second examinations (HCFMUSP, November 2003 to December 2004).

\begin{tabular}{lccccc}
\hline & \multicolumn{2}{c}{ Control $(\mathrm{n}=23)$} & \multicolumn{2}{c}{ Exercise $(\mathrm{n}=23)$} \\
& $r$ & $P$ & $r$ & $P$ \\
\hline 1st examination & 0.729 & $<.001$ & 0.739 & $<.001$ \\
2nd examination & 0.852 & $<.001$ & 0.626 & $<.001$ \\
\hline
\end{tabular}

Table 7 - Spearman correlation coefficients between functional evaluation of the pelvic floor (FEPF) and perineometry with biofeedback (PWB) obtained at the first and second examinations (HCFMUSP. November 2003 to December 2004).

\begin{tabular}{lccccc}
\hline & \multicolumn{2}{c}{ Control $(\mathrm{n}=23)$} & \multicolumn{2}{c}{ Exercise $(\mathrm{n}=23)$} \\
& $r$ & $P$ & $r$ & $P$ \\
\hline 1st examination & 0.768 & $<.001$ & 0.736 & $<.001$ \\
2nd examination & 0.828 & $<.001$ & 0.643 & $<.001$ \\
\hline
\end{tabular}




\section{DISCUSSION}

If performed during pregnancy, PFMT is a safe and effective technique that restores or develops pelvic floor muscle strength and helps women control this musculature during pregnancy and during the expulsive phase of labor. ${ }^{8}$ The PFMT technique teaches patients how to contract and relax the musculature. Uterine contraction causes the patient to contract the perineum due to fear and lack of awareness of the fact that this movement will impair expulsion of the fetus. The beneficial effects of PFMT might therefore be of great importance. ${ }^{8}$

The main objective of the study was to determine the effects of PFMT evaluated through FEPF and perineometry. An increase in pelvic floor muscle strength during pregnancy was observed upon FEPF both in the control and in the exercise groups, with this increase being significantly higher in the latter. The increase in pelvic floor muscle strength observed in the control group can be explained by the perception of the perineal region on the part of the patient during evaluation, since the gain in muscle strength could not have occurred so fast otherwise. Several studies ${ }^{23}$ have shown that more than $30 \%$ of women do not contract their pelvic floor muscles correctly at their first consultation; this is referred to as paradoxical contraction of the pelvic floor muscles. Within this context, patients who showed this type of error were excluded from the study, and patients showing other possible errors such as contracting the gluteal muscles, hip adductor, or abdominal muscles instead of the pelvic floor muscles were corrected with appropriate monitoring and feedback. ${ }^{16}$ Results from previous studies suggest that the training protocol and a skilled physiotherapist are important. ${ }^{4-8}$ In this study, a skilled physiotherapist was leading the training protocol and motivated the patients to follow the protocol.

The training protocol and the measuring of strength in the present study was the same described by Bo. ${ }^{5}$ Although there are different PFMT protocols for pregnant women, ${ }^{4-8}$ the main difference between these protocols is the number of muscle contractions performed and the length of time each contraction is held. Based on this difference, choosing an exercise protocol depends on the characteristics of the pregnant population being studied.

Analysis of the correlation between perineometry with biofeedback and perineometry without biofeedback and FEPF in our study revealed a positive and significant correlation between exams at the 2 points in time evaluated during pregnancy. This is in agreement with the study of Isherwood and Rane ${ }^{15}$ who reported a positive and significant correlation between FEPF and perineometry. This correlation is important because it suggests that in the absence of a perineometer, FEPF can reliably be used for pelvic floor assessment when performed by a professional who is specialized in pregnancy and prenatal care. Therefore, clinicians can use this method of assessment in their prenatal-care practice to reinforce the importance of carrying out regular PFMT. ${ }^{15}$ However, some authors ${ }^{16}$ found agreement between testers in only $45 \%$ and $47 \%$ of the tested cases, respectively, using Laycock's modified Oxford Scale. Jeyaseelan et $\mathrm{al}^{24}$ concluded that inter-tester reliability should not be assumed and needs to be established when 2 or more clinicians are involved in pretreatment and post treatment assessment. In the present study, the same skilled physiotherapist performed all measurement.

At the 2nd examination of the pelvic floor muscles by perineometry, an increase in vaginal pressure was observed in the two groups; however, it was significantly higher in the exercise group. These findings are in accordance with other studies in which patients underwent pelvic floor muscle training during pregnancy and early puerperium. ${ }^{4,7}$ Perineometry with biofeedback demonstrated a higher level of vaginal strength at the 2nd examination in both the exercise and control groups. This suggests that the visual stimulus inherent to perineometry with biofeedback markedly contributed to the improvement of pelvic floor contraction by helping the patient to be perceptive regarding the pelvic floor muscles. The use of biofeedback improves the perception of the pelvic floor muscles and may thus significantly increase vaginal strength, an observation also emphasized by Meyer. ${ }^{18}$ In agreement with the study by Morkved, ${ }^{7}$ we also observed an increase in perineometry values at the 2 nd examination, with these values always being higher in the group undergoing PFMT compared to the control group.

Notably, there are several types of vaginal strength devices available to measure vaginal squeeze strength, all with different device sizes and technical parameters. ${ }^{25}$ Although some authors ${ }^{15}$ describe the perineometer as a gold standard for contraction strength measurements, the scales obtained with different methods cannot be compared, and there is no standard recommendation for the minimum desirable perineometric reading when assessing the strength of a pelvic floor contraction, especially for pregnant women. ${ }^{15,16}$

Within the limitations of the present study, the device used in this study had not been previously validated. However, it was certified by the Brazilian National Sanitary Surveillance Agency (ANVISA), and its calibration was ascertained 3 times during the study by the Institute for Weights and Measures. Another limitation of the study was the lack of randomization due to practical considerations.

Other notable issues exist regarding the use of several methods of measuring pelvic floor contraction strength in pregnancy. There is the need for studies focusing on the 
construction of normal curves for vaginal strength in nulliparous women, a curve that is not yet available in medical literature but would be necessary as a parameter for comparison. Body changes throughout pregnancy, such as weight gain, can influence the measurements obtained by these methods. In the present study, patient weight gain was homogeneous between the two groups studied.

One last question should be addressed: can physiologic changes during pregnancy, such as local muscle and mucosa edema, modify vaginal sensibility and therefore influence the measurements taken by digital examination or by a perineometer? Further randomized studies with larger numbers of pregnant women are necessary to clarify these issues.

In conclusion, this study shows that pelvic floor muscle training resulted in a significant increase in pelvic floor muscle strength during pregnancy. A positive and significant correlation between functional evaluation of the pelvic floor muscle and perineometry was observed during pregnancy.
Oliveira C, Lopes MAB. Longo e Pereira LC, Zugaib M. Efeitos da cinesioterapia no assoalho pélvico durante a gravidez. CLINICS. 2007;62(4):439-46.

INTRODUÇÃO: A gravidez traz importantes modificações hormonais e anatômicas que têm efeito sobre a musculatura do assoalho pélvico. A cinesioterapia aplicada à musculatura do assoalho pélvico na gestação pode ser grande aliada no controle das alterações músculo-esqueléticas.

OBJETIVOS: Avaliar efeitos da cinesioterapia no assoalho pélvico durante a gravidez, por meio da perineometria com e sem "biofeedback" e da avaliação funcional do assoalho pélvico, e correlacionar os valores da avaliação funcional com as perineometrias.

MÉTODOS: Estudamos 46 gestantes nulíparas em seguimento pré-natal no Departamento de Obstetrícia do Hospital das Clínicas da Universidade de São Paulo, entre novembro de 2003 e dezembro de 2004, com até 20 semanas de gestação, atendidas no Setor de Baixo-Risco, divididas em dois grupos: Grupo exercício (23 casos): pacientes submetidas à cinesioterapia para a musculatura do assoalho pélvico; e grupo controle (23 casos): sem a prática da cinesioterapia. Por 12 semanas, até a $36^{\mathrm{a}}$ semana, seguiuse um protocolo, com treinamento de 60 minutos semanais, executando-se quatro séries de 10 contrações destes músculos com seis segundos de manutenção e 12 segundos de 
relaxamento, em decúbitos distintos. Realizaram-se 2 avaliações: $1^{\text {a }}$ (até 20 semanas) e $2^{\text {a }}$ (36 semanas gestacionais), por meio da avaliação funcional do assoalho pélvico e da perineometria.

RESULTADOS: Na avaliação funcional do assoalho pélvico, tanto o grupo exercício como o grupo controle apresentaram aumento significativo da $1^{\text {a }}$ avaliação para a $2^{a}$ avaliação. Para a perineometria sem "biofeedback", na $2^{\mathrm{a}}$ avaliação, somente o grupo exercício obteve aumento significativo, com $\mathrm{p}<0,001$. Quanto à perineometria com "biofeedback", tanto o grupo exercício como o controle tiveram aumento significativo nos valores, porém o delta porcentual foi maior no grupo exercício. Houve correlação significativa e positiva entre a avaliação funcional do assoalho pélvico e as perineometrias sem e com "biofeedback" nas duas primeiras avaliações.

CONCLUSÕES: Os efeitos da cinesioterapia nos músculos do assoalho pélvico revelaram aumento significativo na pressão e na força durante a gestação. Durante o período gestacional houve correlação positiva e significativa entre a avaliação funcional do assoalho pélvico e as perineometrias.

UNITERMOS: Técnicas de exercício e movimento. Soalho pélvico. Doenças musculoesqueléticas. Períneo. Gravidez e Puerpério.

\section{REFERENCES}

1. Allen RE, Hosker GL, Smith ARB, Warrell DW. Pelvic floor damage and childbirth: a neurophysiological study. Br J Obstet and Gynaecol. 1990;97:770-9.

2. Schussler B, Anthuber C, Warrell D. In: Pelvic floor re-education: the pelvic floor before and after delivery. Springer-Verlag: London; 1994. p. 105-110.

3. Bourcier A. Urodinamique et réadaptation em urogynecologie. Editions Vigot. Paris; 1986. p. 209-21.

4. Morkved S, Bo K. The effect of post-natal exercises to strengthen the pelvic floor muscles. Acta Obstet Gynecol Scand. 1996;75:382-5.

5. Bo K, Talseth T, Holme I. Single blind, randomized controlled trial of pelvic floor exercises, electrical stimulation, vaginal cones, and no treatment in management of genuine stress incontinence in women. BMJ. 1999;318:487-93
6. Sampselle CM, Miller JM, Mims BL, Dlancey JO, Asthon-Miller JA, Antonakos CL. Effect of pelvic muscle exercise on transient incontinence during pregnancy and after birth. Obstet Gynecol. 1998;91:406-12.

7. Morkved S, Bo K, Schei B, Salvesen KA. Pelvic floor muscle training during pregnancy to prevent urinary incontinence: a single-blind randomized controlled trial. Am College of Obstet and Gynecol. 2003;101:313-9.

8. Salvesen KA, Morkved S. Randomised controlled trial of PFMT during pregnancy. BMJ. 2004;329:378-80.

9. Dougherty MC, Bishop KR, Abrams RM, Batich CD, Gimotty PA. The effect of exercise on the circumvaginal muscles in postpartum women. J Nurse Midwifery. 1989;34:9-14

10. Guyton AC, Hall JE. Contração músculo-esquelética [Musculoskeletal contraction] In: Fisiologia Médica [Medical Physiology]. 9th ed. Rio de Janeiro: Guanabara-Koogan; 1999. p.75. (Portuguese). 
11. Reilly EC, Freeman RM, Waterfield MR, Waterfield AE, Steggles P, Pedlar F. Prevention of postpartum stress incontinence in primigravidae with increased bladder neck mobility: a randomized controlled trial of antenatal pelvic floor exercises. BJOG 2002;109:68-76.

12. Hahn I, Milson I, Ohlsson BL, Ekelund P, Uhlemann C, Fall M. Comparative assessment of pelvic floor function using vaginal cones, vaginal digital palpation and vaginal pressure measurements. Gynecol Obstet Invest. 1996;41:269-74.

13. Brink CA, Wells TJ, Sampselle CM, Taillie ER, Mayer R. A digital test for pelvic muscle strength in women with urinary incontinence. Nurs Res. 1994:43:352-6.

14. Ortiz CO, Coya NF Ibañez G. Evaluacion functional del piso femenino (Classificacion Funcional). Bol Soc Latinoam Uroginecol Cir Vaginal. 1996;1(3/4):5-9.

15. Isherwood PJ, Rane A. Comparative assessment of pelvic floor strength using a perineometer and digital examination. Br J Obstet Gynecol. 2000;107:1007-11.

16. Bo K, Sherburn M. Evaluation of female pelvic-floor muscle function and strength. Physical Therapy. 2005;85:269-82.

17. Ortiz CO, Coya NF. Dynamic assessment of pelvic floor function in women using the intravaginal device test. Int Urogynecol J. 1996;7:317-20.
18. Meyer S, Hohlfeld P, Achtari C, De Grandi P. Pelvic floor education after vaginal delivery. Obstet Gynecol. 2001;97:673-7.

19. Rosner, B. Fundamentals of biostatistics. 2nd ed. Boston: PWS Publishers; 1986. p. 584

20. Timm NH. Multivariate analysis with applications in educations and psychology. Monterrey: CA Brooks/Cole; 1975.

21. Vonesh EF, Schork MA. Sample size in the multivariate analysis of repeated measurements. Biometrics. 1986;42:601-10.

22. Rosso P. A new chart to monitor weight gain during pregnancy. Am J Clin Nutr. 1985;41:644-52.

23. Bump R, Hurt WG, Fantl JA, Wyman JF. Assessment of Kegel exercise performance after brief verbal instruction. Am J Obstet Gynecol. 1991;165:322-9.

24. Jeyaseeland S, Haslam J, Winstanley J. Digital vaginal assessment: an inter-tester reliability study. Physiotherapy. 2001;87:243-50

25. Bo K, Raastad R, Finckenhagen HB. Does the size of the vaginal probe affect measurement of pelvic floor muscle strength? Acta Obstet Gynecol Scand. 2005;84:129-33. 